\title{
Research on Innovation and Entrepreneurship Education of Entrepreneurial University
}

\author{
Chongwen Sun \\ ${ }^{1}$ Schools of Management, Wuhan University of Technology, Wuhan 435400, China. \\ ${ }^{2}$ Hubei Water Resources Technical College, Wuhan \\ 21665307@qq.com
}

Keywords: Entrepreneurial universities, teaching function, path.

\begin{abstract}
Under the era of "mass entrepreneurship and innovation", innovation and entrepreneurship have become the main driving force for social development in China. As a major battleground, universities have been given more economic missions. And entrepreneurial universities have injected new teaching ideas with unique development form to deepen the reform of education. Entrepreneurial universities are analyzed in this paper on the basis of the talents cultivation target and how the organizational culture, course system and entrepreneurial resources realizing teaching features, including teaching objectives, contents and means, provide certain reference for the construction of entrepreneurial university.
\end{abstract}

\section{Introduction}

"Development strategy for national innovation drive outline clearly pointed out that to promote the education innovation, reform of talent cultivation mode, practical and the innovation thinking, creativity and the cultivation of scientific spirit and social responsibility throughout the whole process of education, improve the high-end innovation talents and industry skills talents" dual support "talent cultivation system, enhancing the innovation foundation. In an age of "public entrepreneurship, peoples innovation" boom, innovation entrepreneurship become the main driving force of social development in our country, and the university as a key battleground, also endowed with more economic mission, which makes higher education into a contradiction, show the talent training and social development presents certain disconnect.

According to the 2017 Mycos research, institute's employment report for Chinese students, the total number of graduates reached 2.95 million in 2017, with both the increment and increase exceeding the previous years. Among them, Hubei province has 430000 college graduates and in view of the college graduates, employment demand is around 20 million, equivalent to five jobs to choose of 1 graduates. However, unemployed people account for $7.5 \%$. Therefore, there is still a structural contradiction between the talent training and talent demand of our university. On the other hand, the shortage of talents makes it more difficult to recruit the right talent. The state council on further do a good job under the new situation the employment business opinion "pointed out: to promote the entrepreneurship, innovation, entrepreneurial innovation to create more employment opportunities, creating new economic and social development. Under the national colleges and universities and the support, immediately after graduating from college students' entrepreneurship rate rose from $1.6 \%$ in 2011 to $3 \%$ in 2017 , but the success rate of less than $1 \%$, and $28 \%$ of the developed countries such as business scale, compared with a $20 \%$ rate in the far.

Innovation in colleges and universities entrepreneurship education is the important way to solve the problem of talent training, although has carried out more than a decade, but is still a weak link, there are many deep problems unresolved, organizational structure and different from the traditional university entrepreneurial university gradually began to accompanied by light and heat. 


\section{Connotation of Entrepreneurial Universities}

The emergence of entrepreneurial university should be to knowledge-based society of a positive response to build an innovation-oriented country, and is in a rapidly changing society to promote comprehensive reform of higher education, improve the modern university system of a practice, and is the inevitable requirement of innovation in entrepreneurship education. At present, there is no uniform standard for the research on the connotation of entrepreneurial universities, mainly along the following two routes:

The first is a "revolutionary" entrepreneurial university, represented by American scholar burton clark, the university of Warwick similar European primary model entrepreneurial university as samples, from the perspective of university organizational transformation, select the five typical university, long-term follow-up investigation, summarize them in the face of rapidly changing external environment and the challenges of complex social demand to make all sorts of change reaction. $\mathrm{He}$ described entrepreneurial university as: on their own, and actively explore on how to enter the business and associated with the business community to innovate, seek a material change in the organizational characteristics, so as to achieve in the future more promising, as "stand up" at the same time, the university of important actors can act according to their own claims [1].

The second is "leading" entrepreneurial university, by the American scholar Henry Mr Bates represented wizz, will be similar at the Massachusetts institute of technology of American research universities as samples, from the perspective of two academic revolution, analyzes the new economic environment, the university how to get the knowledge as the source power, play the advantages of scientific research and talent agglomeration, through the function of expanding cooperation with industry, university functions from the original teaching to scientific research, and then from scientific research to serve the society. Corresponding to it is the change of university model, namely, teaching, research and entrepreneurial model. He described entrepreneurial university as: often get the government's policy to encourage university and its component members growing interest in the benefited from an intellectual capital, the interest and desire and accelerate blurred the line between academic institutions and the company. In order to explain the mechanism of the interaction between government, university and industry in the innovation and entrepreneurship process, he proposed the "three spiral theory" model [2].

To sum up, this paper argues that entrepreneurial university is different from the traditional development model of new academic organization, can quickly adapt to changing social needs, and timely adjust accordingly, in cooperation with government, industry, the role of knowledge innovation main body, take the national and regional economic development mission. Entrepreneurial university social service function on the business development, at the head of the teaching and scientific research, promote academic capital transformation, cultivate interdisciplinary talents with innovative entrepreneurial spirit of the university.

\section{Entrepreneurial Universities' Objective of Cultivating Talents}

There is a wide variety of professional stage of popularization of higher education, demand is also changing, presents the interdisciplinary characteristics, technology integration, knowledge integration, and this change is complicated and unpredictable, education is faced with more and more uncertainty, these are to bring huge challenges, different levels of university and entrepreneurial university as a branch of higher education, with its different from the traditional model of the development of university shows its unique advantages, in the face of the complex social demand, timely response, show some dynamic, can form a diversified composite flexible combination corresponding professional major, and timely reflect them in the teaching, scientific research, cultivate comprehensive talents. As a new educational concept, it is a blend of traditional college talents training target, and the purpose of the entrepreneurial university is not simply in order to promote college students' employment, entrepreneurship, but rather a including consciousness training, ability to ascend, such as environmental awareness, innovative thinking to develop and entrepreneurial 
personality cultivation, grasp opportunities, integrate resources, create greater personal and social value. Therefore, the goal of cultivating talents of entrepreneurial universities can be divided into three levels, namely, the value level, the theoretical level and the practical level.

The value level is mainly reflected in the cultivation of consciousness, which has certain preexistence. Consciousness cultivation mainly people about the importance of innovative entrepreneurial values, cognitive level and the formation of the attitude towards the innovative undertaking, and with this attitude to regulate and adjust their activities of a stable situation [3]. Aiming at the cultivation of the consciousness, entrepreneurial universities need to let students understand why entrepreneurship, and the concept of entrepreneurship, characteristics, essential accomplishment and related basic knowledge, master entrepreneurial activities to carry out the general process of preliminary. As education minister Yuan Guiren indicated on the two sessions in 2015, cutting into the business-pioneering education with school education, and not let each student as an entrepreneur, the fundamental purpose is to through entrepreneurship education, make students form the innovative idea, innovative thinking and innovative quality, to implement the strategy of innovation to drive the development of the service to the nation [4].

The theory level is mainly the improvement of students' comprehensive ability, which mainly solves the problem of how to start a business. Entrepreneurial university will entrepreneurship and professional education system for organic integration, technology innovation as the springboard, to cultivate college students' vision, decision-making, organization and coordination ability, critical thinking and leadership, including self-employed and post start-up entrepreneurs necessary quality, improve the ability of entrepreneurship.

The practice level is mainly to guide college students to understanding of today's social enterprises operating environment, mastering the technique of commercial mode and strategy, to grasp the business opportunities and control business risk.

Value, theory and practice are a process of step by step, which is also the process from mass to elite, and also the process of personalized culture.

\section{Teaching Characteristics of Entrepreneurial University}

Entrepreneurial university reflects on the basis of the organizational culture of teaching, curriculum system as the core, resources as the key system of education, teaching activity is intended to provide students with entrepreneurial university disciplines and specialties and venture into a personalized learning experience, the learning experience for students' interests, needs, goals, resources, and past learning experience, choice and control in the strong entrepreneurial culture learning rights, higher learning motivation, personal relevance and entrepreneurship to improve students' learning initiative, cultivate the innovative entrepreneurial talent. The characteristics of the teaching function of entrepreneurial university are shown in figure 1:

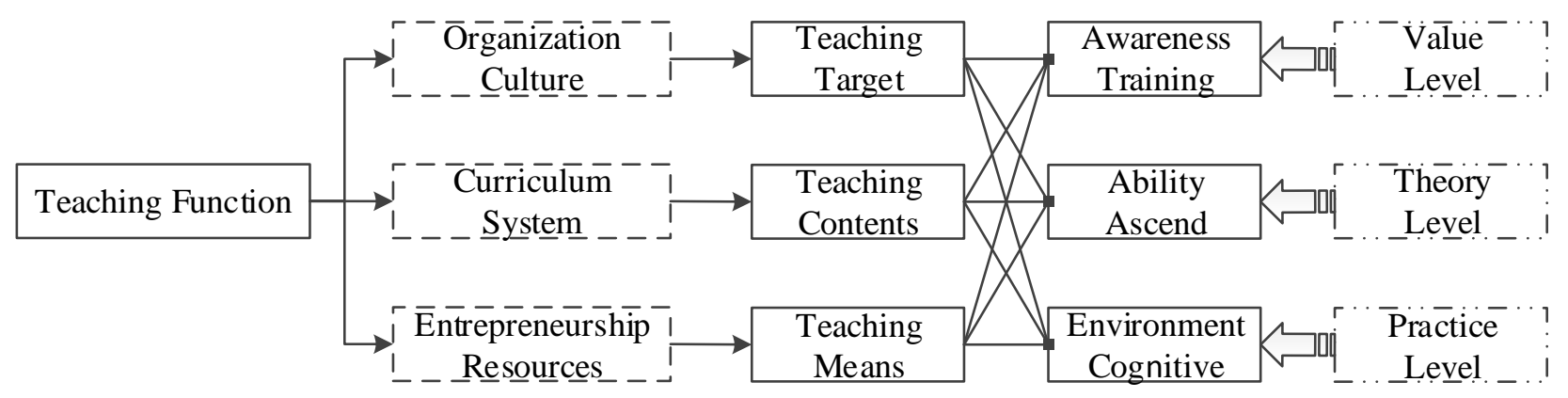

Fig. 1 Characteristics of the Teaching Function of Entrepreneurial Universities

\subsection{To realize the Orientation of Teaching Objectives by Multiple Organizational Culture.}

Organizational culture is a kind of basic model assumption, namely the organization within the external adaptation and try to solve the problems appeared in the process of integration, invention, 
discovery, or to develop a basic model, and this model is quite effective, therefore, it is as a kind of right way to teach new members, to think or feel some of the problems associated [5]. The entrepreneurial university one of the salient features different from other traditional college, the present a pluralistic, open and inclusive characteristics different from traditional university organization culture, and throughout the university, led the teachers' teaching behavior, make the teaching goal of directivity, promote the development of entrepreneurial activities between teachers and students, participation and entrepreneurial atmosphere, formed by a kind of intangible restriction, guarantee and regulate the personalized, diversified teaching activities. Therefore, the first point of the teaching activities of entrepreneurial universities is to form an administrative and academic culture that is centered on entrepreneurship and including campus culture, and they are highly unified. A series of behavior, the value is related to entrepreneurship, the rule of thought combining dominant culture, is the core is the spiritual shape, reflects the change and challenge, innovation, the pursuit of excellence, risk-taking, and many aspects, such as tolerance of failure, and administrative and academic culture under the guidance of the dominant ideology, its also quietly changing, under the guarantee of system were reflected in the form of service and cooperation, finally make the teaching get distillation process.

\subsection{The Dynamic Curriculum System is the Core to Realize the Individuation of Teaching Content.}

For the teaching function of entrepreneurial university curriculum system is the key construction part, different from the traditional development mode based on professional disciplines, it focused more on through the establishment of professional mode based on subject to realize the flexible curriculum system. In fact, knowledge itself does not promote innovation. Only by combining different knowledge and internalization can be closely connected with innovation. Therefore, the curriculum system of entrepreneurial universities is a modular course based on the discipline of the professional system, which brings out the personalized features of the teaching content, specifically:

Dock on the one hand, the changing social needs, through the "discipline, professional for use" organizational structure of the different disciplines are combined, interdisciplinary professional develops all kinds of subjects. The academic organization structure will be as a substantive discipline, to provide different professional, including courses, services, teachers, all kinds of resources, and the construction of the professional is the school as a whole, through a similar interdisciplinary research organizations, based on the deep research in the current market and industry. This cross-departmental horizontal professional organization and the university's traditional longitudinal discipline organization and other cross-sections, together form the matrix structure of university organization. In this way, we can make full use of resources, respond quickly to market demands, and cultivate the interdisciplinary talents with the discipline as the support.

On the other hand, the curriculum presents a modular approach based on the "technical logic system". Curriculum is the core carrier of teaching function, and also the focus of implementation of innovation and entrepreneurial teaching objectives. In the teaching practice "technical logic system", in the face of changing cross compound professional, modular processing of course form including general education, professional education, modular curriculum system, practice education, etc. Around a specific content, specific topics will be related courses together, forming a detectable, same size and take credit of different function modules, each module of the start time and the course number are fixed, is beneficial to the random combination between them, at the same time, the different modules together, forming "module pool", can be applied to different specialty, different schools, even achieve resource sharing face-to-face.

This kind of curriculum system enables teachers to adjust and enrich the content of the teaching plan and outline on the basis of teaching plan and outline, and customize personalized teaching.

\subsection{To Diversify the Teaching Form with Open Source of Entrepreneurship.}

Entrepreneurial university is not just through education to help students set up their own business or find a suitable career, what is more important to participate in one of the students with excellent learning experience as well as part of the resource needed, to help students to achieve. University as an independent individual, with government and industry to maintain production, scientific research and 
application of benign interaction system, from the fringes of society into the center of the social economy, gradually established a pioneer park, derivative company and incubators, such as hybrid organization, speed up the pace of the entrepreneurship education from campus to society.

From the perspective of teachers, on the one hand, the teacher as a leader of the teaching and practice activities, widely participate in social entrepreneurship practice, improved the recognition of grasp the business opportunities and business development trend of agility, at the same time, through the way of transformation of the academic capital partnerships with industry to establish a scientific research, the feedback to entrepreneurship education teaching, constantly adjust the teaching form, to make it more focus on practice training. On the other hand, the school undertakes some teaching and guiding tasks by hiring some people with academic background and entrepreneurial experience as part-time teachers.

From the perspective of the college students' entrepreneurial university through in-depth cooperation between colleges and the enterprise needs to give priority to sources of transverse as college students' entrepreneurial projects, in pioneer park and similar incubator, money to solve the most attention, and the problem of lack of experience and through practice, promote the competitiveness of the job. This kind of business is different from "opportunity, entrepreneurial" and "necessity entrepreneurship", but make full use of academic resources, through the way of capitalization operation, presents the "academic entrepreneur" has the academic resources, continuous innovation power.

\section{Summary}

At home, especially constructing an innovative country and since the national strategy of building the world-class university, constantly enrich relevant content and entrepreneurial university gradually become optional modes of development of colleges and universities in our country. In fact, entrepreneurial university as a branch of higher education, has not changed or beyond the traditional university should have the teaching, scientific research and social service three big functions, any university can carry on the transformation to it, but are not suitable for choosing business. Therefore, most scholars have focused on the transformation of entrepreneurial university in the transformation path, and neglected the training and shaping of innovative entrepreneurial talents.

In practice, some local colleges earlier raised the banner of the entrepreneurial university, in a professional setting, personnel training target, and to some extent, the reform on policy support, continuously explore new mode of production, on the outside of the develop a new source of income, on the basis of further regional economic development, but mostly tend to academic entrepreneurship path, not according to their own school-running characteristics, completely rooted in the function of university, into a state of contradictions. Therefore, this paper attempts from the Angle of the teaching function to talent training objectives as the breakthrough point, analysis of entrepreneurial university curriculum system, as well as the construction of entrepreneurial culture, entrepreneurial resources transformation path for the current our country entrepreneurial university entrepreneurship education to provide certain reference and innovation.

\section{References}

[1]. Burton Clark. Establishment of Entrepreneurial University: the Way of Organizational Transformation [M]. Beijing: People Education Press, 2003:2,42.

[2]. Henry Ezkowitz et al.. University and Global Knowledge Economy[M]. Nanchang: Jiangxi Education Press, 1999:228.

[3]. Guo Fengzhi. Innovative Consciousness: an Important Spiritual Resource and Power to Stimulate Creativity [J]. Scientific Socialism, 2002 (5) :51-52.

[4]. People's Daily online: http://edu.people.com.cn/n1/2016/0310/c1006-28189359.html.

[5]. Pettire A. M.. On Studying Organization Culture [J]. Administrative Science Quarterly,1997, V24:570-581. 